\title{
Corrigendum to "Sphingosine-1-Phosphate Signaling in Immune Cells and Inflammation: Roles and Therapeutic Potential"
}

\author{
Masayo Aoki, ${ }^{1,2}$ Hiroaki Aoki, ${ }^{1,2}$ Rajesh Ramanathan, \\ Nitai C. Hait, ${ }^{2}$ and Kazuaki Takabe ${ }^{1,2,3}$ \\ ${ }^{1}$ Division of Surgical Oncology, Department of Surgery, Virginia Commonwealth University School of Medicine and \\ Massey Cancer Center, West Hospital 7-402, 1200 East Broad Street, P.O. Box 980011, Richmond, VA 23298-0011, USA \\ ${ }^{2}$ Department of Biochemistry \& Molecular Biology, Virginia Commonwealth University School of Medicine and Massey Cancer Center, \\ West Hospital 7-402, 1200 East Broad Street, P.O. Box 980011, Richmond, VA 23298-0011, USA \\ ${ }^{3}$ Breast Surgery, Roswell Park Cancer Institute, Elm \& Carlton Streets, Buffalo, NY 14263, USA
}

Correspondence should be addressed to Kazuaki Takabe; kazutakabe@gmail.com

Received 16 August 2016; Accepted 4 September 2016

Copyright (c) 2016 Masayo Aoki et al. This is an open access article distributed under the Creative Commons Attribution License, which permits unrestricted use, distribution, and reproduction in any medium, provided the original work is properly cited.

In the article titled "Sphingosine-1-Phosphate Signaling in Immune Cells and Inflammation: Roles and Therapeutic Potential" [1], there was an error in the "FTY720 and Lymphopenia" section, where the sentence "p-FTY720 causes continued cAMP signaling that is not dependent on S1P1R redistribution and induces functional antagonism of $\mathrm{Ca}^{2+}$ signaling after transient stimulation" should be corrected to "p-FTY720 causes continued cAMP signaling that is not dependent on S1PR1 redistribution and induces functional antagonism of $\mathrm{Ca}^{2+}$ signaling after transient stimulation."

\section{References}

[1] M. Aoki, H. Aoki, R. Ramanathan, N. C. Hait, and K. Takabe, "Sphingosine-1-phosphate signaling in immune cells and inflammation: roles and therapeutic potential," Mediators of Inflammation, vol. 2016, Article ID 8606878, 11 pages, 2016. 


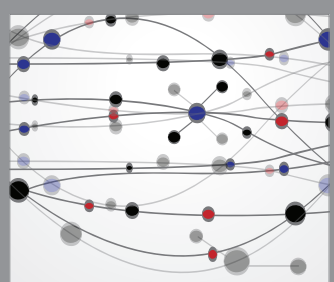

The Scientific World Journal
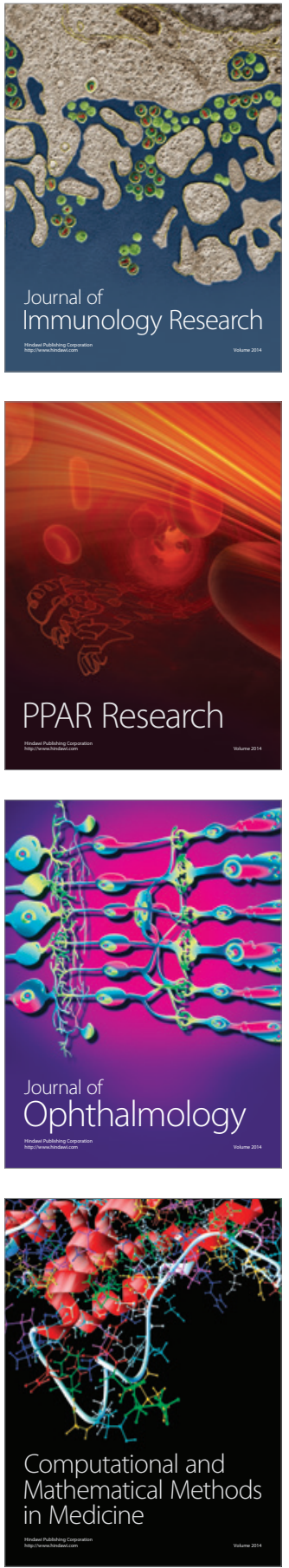

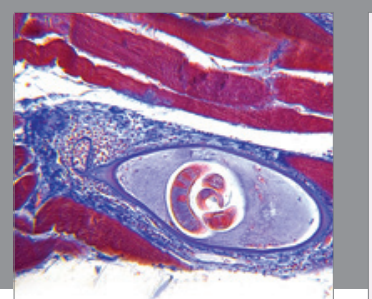

Gastroenterology Research and Practice

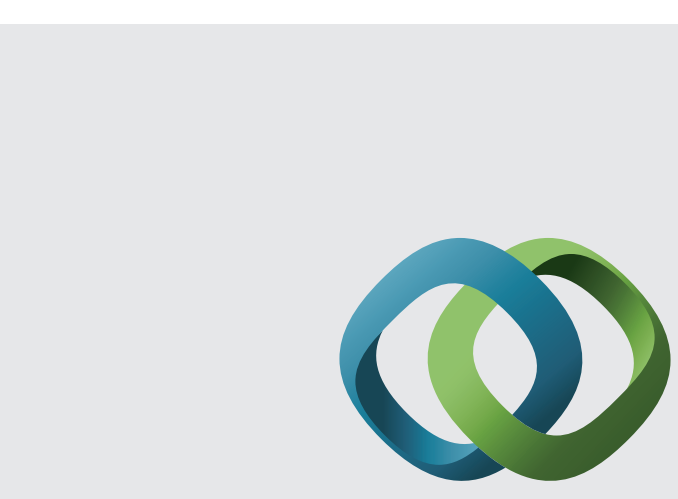

\section{Hindawi}

Submit your manuscripts at

http://www.hindawi.com
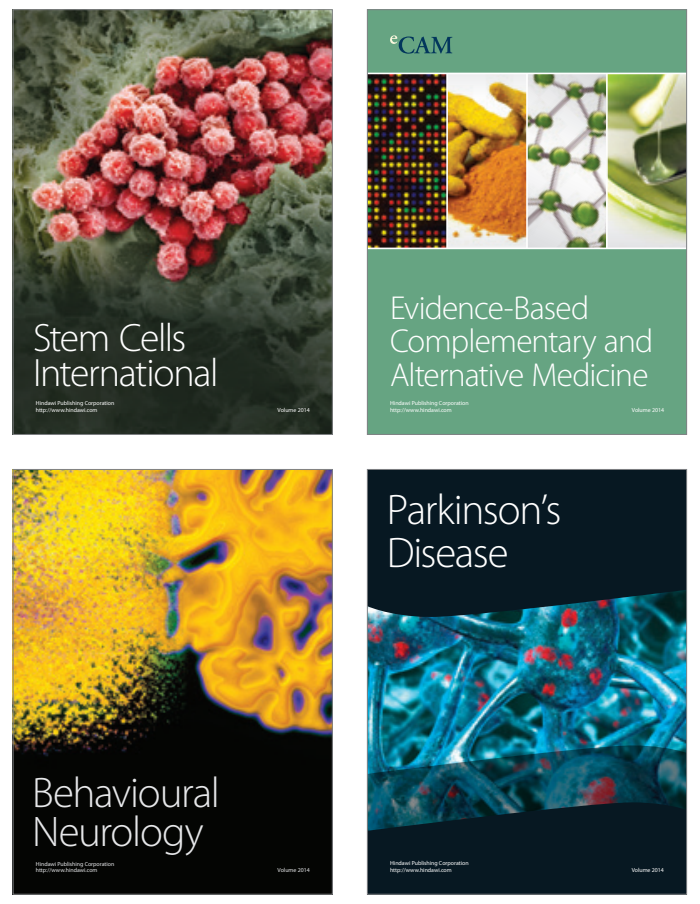
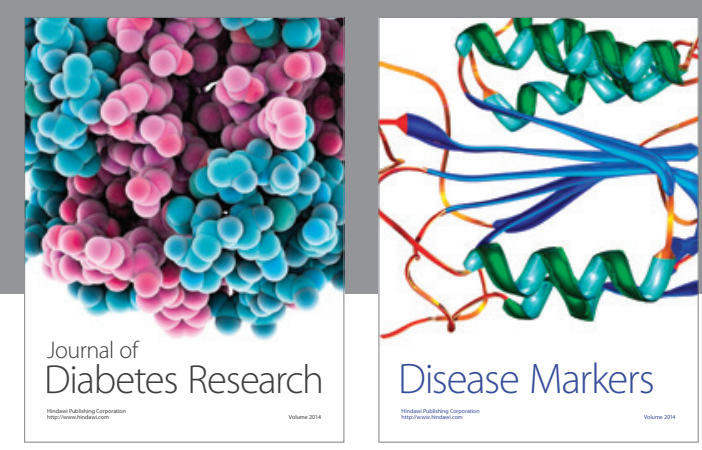

Disease Markers
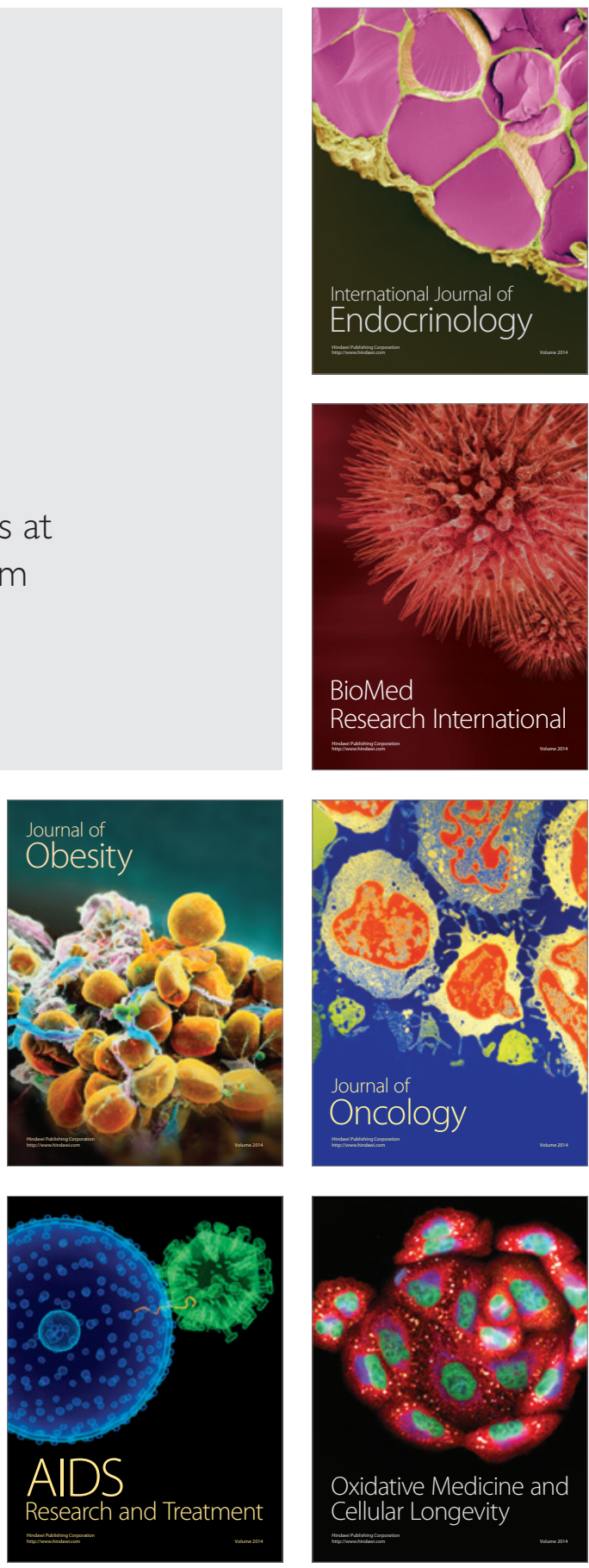